\title{
Arroz: composição e características nutricionais
}

\author{
Rice: composition and nutritional characteristics
}

Melissa Walter ${ }^{\mathrm{I}}$ Enio Marchezan ${ }^{\mathrm{II}}$ Luis Antonio de AvilaII

\section{RESUMO}

Devido à importância do arroz na dieta, sua composição e suas características nutricionais estão diretamente relacionadas à saúde da população. Este cereal constitui-se em fonte de energia, devido ao alto teor de amido, fornecendo também proteínas, lipídios, vitaminas e minerais. O presente trabalho de revisão objetivou examinar a composição do arroz, suas características nutricionais e o melhoramento destas através da genética. São observadas variações na composição do arroz, tanto devido ao genótipo quanto ao processamento, afetando as características nutricionais. $\mathrm{O}$ arroz apresenta efeito positivo na prevenção de diversas doenças crônicas devido a diferentes constituintes, e sua composição vem sendo melhorada através da genética, obtendo-se grãos com características nutricionais mais interessantes.

Palavras-chave: arroz, composição, carboidratos, proteínas, lipídios, compostos fenólicos.

\section{ABSTRACT}

Due to the importance of rice in the diet, its composition and nutritional characteristics are related to human's health. This cereal is a source of energy, due to its high starch content, also providing proteins, lipids, vitamins and minerals. The present review aimed at examining rice composition, its nutritional characteristics, and the improvement of these characteristics through genetic modification. Variations in rice composition are observed due to genotype and processing, affecting nutritional characteristics. Rice has a positive effect on the prevention of several chronic diseases due to different constituents, and its composition has been improved through genetic modifications, resulting in grains with more interesting nutritional characteristics.

Key words: rice, composition, carbohydrates, proteins, lipids, phenolic compounds.

\section{INTRODUÇÃO}

O arroz (Oryza sativa) é um dos cereais mais produzidos e consumidos no mundo, caracterizandose como principal alimento para mais da metade da população mundial. Sua importância é destacada principalmente em países em desenvolvimento, tais como o Brasil, desempenhando papel estratégico em níveis econômico e social. A produção anual de arroz é de aproximadamente 606 milhões de toneladas. Nesse cenário, o Brasil participa com 13.140.900t (2,17\% da produção mundial) e destaca-se como único país não-asiático entre os 10 maiores produtores (FAO, 2006).

Apenas uma pequena quantidade de arroz é consumida como ingrediente em produtos processados, sendo seu maior consumo na forma de grão. O arroz é uma excelente fonte de energia, devido à alta concentração de amido, fornecendo também proteínas, vitaminas e minerais, e possui baixo teor de lipídios. Nos países em desenvolvimento, onde o arroz

\footnotetext{
'Programa de Pós-graduação em Agronomia, Universidade Federal de Santa Maria (UFSM), Santa Maria, RS, Brasil.

IIDepartamento de Fitotecnia, Centro de Ciências Rurais (CCR), UFSM, 97105-900, Santa Maria, RS, Brasil. Email: emarchezan@terra.com.br. *Autor para correspondência.
} 
é um dos principais alimentos da dieta, ele é responsável por fornecer, em média, 715kcal per capita por dia, 27\% dos carboidratos, 20\% das proteínas e 3\% dos lipídios da alimentação. No Brasil, o consumo per capita é de $108 \mathrm{~g}$ por dia, fornecendo $14 \%$ dos carboidratos, $10 \%$ das proteínas e 0,8\% dos lipídios da dieta (KENNEDY et al., 2002). Portanto, devido à importância do arroz na dieta de grande parte da população, sua qualidade nutricional afeta diretamente a saúde humana.

Diversos componentes do arroz presentes no farelo e/ou no endosperma têm sido relacionados a diferentes efeitos no organismo. Pesquisadores relatam efeitos benéficos à saúde, como auxílio no controle da glicose sanguínea, redução dos lipídios séricos e da pressão arterial, entre outros, auxiliando na prevenção e no controle de doenças crônicas, como diabetes e doenças cardiovasculares (MILLER et al., 1992; KOIDE et al., 1996; QURESHI et al., 1997; RONG et al., 1997; XIA et al., 2003). Esses efeitos estão relacionados à presença dos compostos no grão, sendo portanto afetados por diferentes fatores, principalmente pela característica genotípica e pelo processamento. Pesquisas vêm sendo desenvolvidas a fim de melhorar a característica nutricional do arroz através do melhoramento genético, sendo que já foram obtidos grãos com maior teor de pró-vitamina A, ferro, zinco e alguns aminoácidos. Esta revisão bibliográfica objetivou examinar a composição do arroz, suas características nutricionais, e o melhoramento destas características através da genética.

Estrutura e composição do grão

O grão de arroz consiste da cariopse e de uma camada protetora, a casca. A casca, composta de duas folhas modificadas, a pálea e a lema, corresponde a cerca de $20 \%$ do peso do grão. A cariopse é formada por diferentes camadas, sendo as mais externas o pericarpo, o tegumento e a camada de aleurona, que representam 5-8\% da massa do arroz integral. A camada de aleurona apresenta duas estruturas de armazenamento proeminentes, os grãos de aleurona (corpos protéicos) e os corpos lipídicos. O embrião ou gérmen está localizado no lado ventral na base do grão, é rico em proteínas e lipídios, e representa 2-3\% do arroz integral. O endosperma forma a maior parte do grão (89-94\% do arroz integral) e consiste de células ricas em grânulos de amido e com alguns corpos protéicos (JULIANO \& BECHTEL, 1985).

Através da descascagem, separa-se a casca da cariopse, obtendo-se o arroz integral. Este pode ser polido para remoção do farelo (pericarpo, tegumento, camada de aleurona e gérmen), que representa 8,514,8\% do arroz integral (JULIANO \& BECHTEL, 1985), obtendo-se o arroz branco polido. Os grãos também podem ser submetidos à parboilização, processo hidrotérmico através do qual se obtém o arroz parboilizado, o qual pode ser consumido na forma integral ou polido.

O arroz é constituído principalmente por amido, apresentando quantidades menores de proteínas, lipídios, fibras e cinzas (Tabela 1). Entretanto, a composição do grão e de suas frações está sujeita a diferenças varietais, variações ambientais, de manejo, de processamento e de armazenamento (ZHOU et al., 2002), produzindo grãos com características nutricionais diferenciadas. Além disso, os nutrientes não estão uniformemente distribuídos nas diferentes frações do grão. As camadas externas apresentam maiores concentrações de proteínas, lipídios, fibra, minerais e vitaminas, enquanto o centro é rico em amido. Dessa forma, o polimento resulta em redução no teor de nutrientes, exceto de amido, originando as diferenças na composição entre o arroz integral e o polido.

\section{Carboidratos}

Os carboidratos são os principais constituintes do arroz. Além do amido, que corresponde a aproximadamente $90 \%$ da matéria seca do arroz polido, também estão presentes açúcares livres e fibra. Enquanto o endosperma é composto principalmente por amido, o farelo e o gérmen apresentam principalmente fibra, contendo pequenas quantidades de outros carboidratos (JULIANO, 1993).

O amido é um homopolissacarídeo composto por cadeias de amilose e amilopectina. As proporções em que estas cadeias aparecem diferem entre genótipos, podendo-se classificar os grãos como ceroso (1-2\% de amilose), conteúdo de amilose muito baixo (2-12\%), baixo (12-20\%), intermediário (20-25\%) e alto (25-33\%) (JULIANO, 1993). O conteúdo de amilose é considerado um dos principais parâmetros para a qualidade tecnológica e de consumo do arroz. De forma geral, grãos com maior teor de amilose apresentam textura mais firme após o cozimento, sendo preferidos em diversos países, como o Brasil, e por isso essa característica é avaliada durante o desenvolvimento de cultivares. Entretanto, outros fatores, como a estrutura das cadeias de amilopectina e o teor de proteína também influenciam essa característica (ONG \& BLANSHARD, 1995).

A concentração de amido no arroz pode variar devido a fatores genéticos e ambientais, como observado por FREI et al. (2003), que obteve teores de amido entre 72 e $82 \%$ em arroz integral de diferentes cultivares. O processamento também influencia o percentual de amido, sendo este maior no arroz branco 
Tabela 1 - Composição centesimal média (\% na matéria seca) de arroz integral, branco polido e parboilizado polido.

\begin{tabular}{lccc}
\hline Constituinte & Arroz integral & Arroz branco polido & Arroz parboilizado polido \\
\hline Amido total & 74,12 & 87,58 & 85,08 \\
Proteínas (N x 5,95) & 10,46 & 8,94 & 9,44 \\
Lipídios & 2,52 & 0,36 & 0,69 \\
Cinzas & 1,15 & 0,30 & 0,67 \\
Fibra total & 11,76 & 2,87 & 4,15 \\
Fibra insolúvel & 8,93 & 1,05 & 1,63 \\
Fibra solúvel & 2,82 & 1,82 & 2,52 \\
\hline
\end{tabular}

Fonte: Adaptado de STORCK (2004)

polido (87,58\%) e no parboilizado polido (85,08\%) comparado ao integral $(74,12 \%)$ (Tabela 1$)$, devido à remoção do farelo. Além das variações na concentração, são observadas diferenças na taxa e extensão da digestão do amido, que podem ser influenciadas pela variação na proporção amilose:amilopectina, processamento do grão, propriedades físico-químicas, tamanho de partícula e presença de complexos lipídioamilose (GODDARD et al., 1984), afetando significativamente algumas respostas metabólicas importantes no organismo. Dessa forma, embora normalmente $\mathrm{o}$ arroz seja classificado como um alimento de alta resposta glicêmica comparado a outros produtos amiláceos, são relatados índices glicêmicos variando de 54 a 121\%, para o arroz branco polido (MILLER et al., 1992).

Uma das principais características relacionadas à resposta metabólica ao arroz consumido é a relação amilose:amilopectina. O maior teor de amilose no arroz, assim como em outros alimentos amiláceos, resulta em menor resposta glicêmica e insulinêmica (GODDARD et al., 1984; MILLER et al., 1992). Essas diferenças fisiológicas são interessantes na prevenção e no tratamento de doenças, como o diabetes, pois a menor digestão e absorção de carboidratos auxilia na manutenção de níveis regulares de glicose no sangue (VELANGI et al., 2005). O consumo de alimentos com menor resposta glicêmica também tem sido associado à redução dos lipídios séricos em pacientes hiperlipidêmicos, diminuindo os riscos de desenvolvimento de doenças cardiovasculares (JENKINS et al., 2002).

$\mathrm{O}$ arroz apresenta pequena quantidade de açúcares livres, localizados principalmente nas camadas externas do grão, sendo sua concentração afetada pela variedade, grau de polimento e processamento. Os principais açúcares no arroz são sacarose (aproximadamente 90\%), glicose e frutose (MATSUO et al., 1995). TRAN et al. (2004) observaram para o arroz integral 685mg $100 \mathrm{~g}^{-1}$ de sacarose e 40mg $100 \mathrm{~g}^{-1}$ de glicose, ocorrendo redução significativa nos teores após o polimento, com valores de 142 e $20 \mathrm{mg}$ $100 \mathrm{~g}^{-1}$ para sacarose e glicose, respectivamente.

Os polissacarídeos não digeridos pelas enzimas no trato gastrintestinal, como celulose, hemiceluloses, amido resistente e pectinas, fazem parte da fração fibra alimentar, que pode ser dividida em solúvel e insolúvel. Sua concentração é maior nas camadas externas do grão e diminui em direção ao centro, resultando em baixa concentração desses componentes nos grãos submetidos ao polimento (Tabela 1). Além das diferenças nos teores de fibra total devido às características genotípicas e de processamento, LAI et al. (2006) observaram diferenças na proporção dos componentes da fibra entre arroz ceroso e não-ceroso. $\mathrm{O}$ arroz ceroso apresentou maior proporção de hemiceluloses (41,1\%), com menor concentração de substâncias pécticas (31,9\%) e celulose (26,9\%). Já o não-ceroso apresentou maior quantidade de substâncias pécticas (43,7\%) e menor de celulose (32,7\%) e hemiceluloses (23,7\%).

A fibra alimentar exerce diferentes funções no organismo humano. Sua capacidade de retenção de água auxilia na prevenção da constipação (WARNER, 1981). Além disso, por não ser digerida, a fibra torna-se disponível para fermentação pela microflora no intestino grosso, com diferentes efeitos no organismo. O maior consumo de fibra na dieta tem sido associado à redução na pressão arterial, na concentração de colesterol total, colesterol LDL e triglicerídeos, e ao controle da glicose sanguínea (LI et al., 2003; BEHALL et al., 2006), auxiliando na prevenção e no controle de algumas doenças crônicas, como diabetes e doenças cardiovasculares. Entretanto, pesquisadores relatam que, em alguns casos, a fibra pode prejudicar a absorção de minerais devido a sua capacidade de ligação e/ou seqüestro destes.

\section{Proteínas}

O conteúdo de proteínas no arroz é considerado baixo, em média 7\%. Entretanto, observase grande variação na concentração desse nutriente, 
com valores entre 4,3 e 18,2\% (LUMEN \& CHOW, 1995), a qual é afetada por características genotípicas, adubação nitrogenada, radiação solar e temperatura durante o desenvolvimento do grão (JULIANO \& BECHTEL, 1985). As proteínas podem ser classificadas em albumina, globulina, prolamina e glutelina, e estão organizadas em dois tipos de corpos protéicos no endosperma. Os corpos protéicos I são grandes estruturas esféricas, com anéis concêntricos, ricos em prolamina. Já os corpos protéicos II não apresentam a estrutura em anéis, e são ricos em glutelina e globulina (ZHOU et al., 2002). No endosperma, a glutelina forma a principal fração, correspondendo a aproximadamente $80 \%$ das proteínas, com menor concentração de albumina e globulina (15\%) e prolamina (5-8\%). Já o farelo apresenta aproximadamente $60 \%$ de albumina, seguido por prolamina e glutelina (27\%) e globulina (7\%) (JULIANO, 1993). Portanto, a composição em proteínas do endosperma difere do farelo.

A composição em proteínas também é afetada pela característica genotípica. LIU et al. (2005b) observaram não só diferença na concentração total de proteínas (7,35-11,47\%) entre genótipos, como também variação nos tipos de proteínas. A maior variação foi observada para a glutelina, com concentração no grão entre 5,9-9,8\%, e correlação positiva com o teor total de proteínas, sendo menores as diferenças para prolamina $(0,69-0,77 \%)$, globulina $(0,37-0,52 \%)$ e albumina (0,38-0,49\%).

A qualidade da proteína depende de seu conteúdo em aminoácidos. Similar a outros cereais, o arroz apresenta a lisina como aminoácido limitante. Entretanto, entre os cereais, o arroz apresenta uma das maiores concentrações de lisina, resultando em balanço de aminoácidos mais completo (JULIANO, 1993). Assim como são observadas variações no teor total de proteínas, também existem diferenças na composição em aminoácidos das proteínas entre o arroz integral e o polido.

Além dos aminoácidos protéicos, o arroz também apresenta pequena quantidade de aminoácidos livres, localizados principalmente no gérmen $(594,9 \mathrm{mg}$ $\left.100 \mathrm{~g}^{-1}\right)$ e no farelo $\left(361,4 \mathrm{mg} 100 \mathrm{~g}^{-1}\right)$, com pequena concentração no endosperma (52,7mg $\left.100 \mathrm{~g}^{-1}\right)$. Entre os aminoácidos livres, predominam aspartato e glutamato, que correspondem a aproximadamente $60 \%$ do total (SAIKUSA et al., 1994).

Para melhorar o perfil de aminoácidos, pesquisas vêm sendo conduzidas visando a aumentar a concentração de certos aminoácidos, como lisina, metionina e cisteína, através de modificação genética. ZHENG et al. (1995) avaliaram a introdução do gene da $\beta$-faseolina, proteína de armazenamento do feijão com conteúdo de lisina relativamente alto (6\%), observando aumento significativo no teor desse aminoácido nos grãos. SINDHU et al. (1997) relataram a integração, a síntese e o acúmulo de legumina, uma proteína de armazenamento da ervilha com maior proporção de lisina, enquanto KATSUBE et al. (1999) relataram a transferência e o acúmulo de glicinina, uma proteína da soja, melhorando a composição em aminoácidos no arroz transformado. Com o objetivo de aumentar o conteúdo de aminoácidos sulfurados (metionina e cisteína), LEE et al. (2003) avaliaram a introdução do gene da proteína $2 \mathrm{~S}$ albumina de gergelim, rica nesses aminoácidos, observando aumento na concentração de metionina (entre 29 e 76\%), cisteína (31 a 75\%) e proteína total $(0,64$ a 3,54\%) no arroz transformado.

\section{Lipídios}

Os lipídios podem ser encontrados organizados em corpos lipídicos (esferossomos) na camada de aleurona, no embrião e no endosperma, ou associados a grânulos de amido (LUMEN \& CHOW, 1995). Entretanto, a maior concentração ocorre no gérmen (1/3 do conteúdo total) e na camada de aleurona. Dessa forma, a concentração de lipídios é maior no arroz integral, sendo reduzida com o polimento, geralmente observando-se concentrações inferiores a $1 \%$ no arroz polido (Tabela 1 ).

O teor de lipídios no grão também é afetado pelas características genotípicas. TAIRA \& ITANI (1988), avaliando grãos integrais de diferentes cultivares, obtiveram valores entre 2,3 e 3,2\%, enquanto os resultados de MANO et al. (1999) variaram entre 2,2 e 2,6\%. Na fração lipídica, foi observada proporção de 84-87\% de lipídios neutros, 5-7\% de glicolipídios e 79\% de fosfolipídios. Na fração lipídios neutros, 63-69\% eram triglicerídeos. A fração de glicolipídios foi formada principalmente por esterilglicosídeos (31-35\%), acilesterilglicosídeos (19-23\%), cerebrosídeos (20-22\%) e diglicosildiacilgliceróis (15-18\%). Na fração fosfolipídios predominaram fosfatidilcolina (41-42\%), fosfatidiletanolamina (31-33\%) e fosfatidilinositol (1517\%) (MANO et al. 1999).

Os principais ácidos graxos no arroz são os ácidos palmítico (16:0), oléico (18:1) e linoléico (18:2), correspondendo a aproximadamente 95\% dos ácidos graxos presentes nos lipídios totais (TAIRA \& ITANI, 1988; MANO et al., 1999). Portanto, o arroz contém proporção significativa de ácidos graxos insaturados, que possuem papel importante em vários processos fisiológicos e que, por não serem sintetizados pelo organismo humano, devem ser supridos pela alimentação.

O óleo do farelo de arroz apresenta uma fração conhecida como matéria insaponificável, 
correspondendo a aproximadamente $4 \%$ do óleo, que consiste de fitosteróis, álcoois triterpênicos, ésteres do ácido ferúlico ( $\gamma$-orizanol), tocóis (vitamina E, tocoferóis e tocotrienóis), entre outros compostos (QURESHI et al., 1997). Aproximadamente 50\% da matéria insaponificável é constituída por $\gamma$-orizanol, um mistura de ésteres de ácido ferúlico com fitosteróis e álcoois triterpênicos (RONG et al., 1997). Estudos têm associado o óleo do farelo de arroz à redução no colesterol total e ao aumento do colesterol HDL, auxiliando na prevenção de doenças cardiovasculares. Esses efeitos são associados não somente à composição em ácidos graxos do óleo, mas também à matéria insaponificável presente, principalmente, $\gamma$ orizanol, tocotrienóis e esteróis, atuando de diferentes formas na redução do colesterol (QURESHI et al., 1997; RONG et al., 1997; VISSERS et al., 2000).

\section{Minerais}

A concentração de minerais difere nas frações do grão. Enquanto no arroz com casca o silício é componente dominante, no arroz integral e polido, destacam-se fósforo, potássio e magnésio. Ferro e zinco, dois minerais essenciais para a saúde humana, estão disponíveis em baixas concentrações no grão (JULIANO \& BECHTEL, 1985).

O conteúdo mineral é grandemente influenciado pelas condições de cultivo, incluindo fertilização e condições do solo, e pelo processamento. De forma geral, os minerais apresentam-se em maior concentração nas camadas externas do grão (Tabela 2), com aproximadamente $72 \%$ no farelo e $28 \%$ no grão polido. Entretanto, alguns minerais apresentam distribuição mais uniforme, como sódio e cálcio, permanecendo no arroz branco polido 63\% do sódio e 74\% do cálcio do arroz integral (ITANI et al., 2002). Embora o arroz integral tenha maior concentração de minerais do que o polido, isso não significa necessariamente maior quantidade de minerais absorvidos pelo organismo, visto que a biodisponibilidade pode ser afetada pela presença de maiores teores de fibra e ácido fítico no arroz integral (JULIANO, 1993).

Com a parboilização, observa-se aumento no conteúdo mineral comparado ao arroz branco polido (Tabela 1), relacionado à migração de minerais das camadas externas para o endosperma durante o processo (JULIANO, 1993). Entretanto, avaliando-se individualmente os minerais, são observados comportamentos diferenciados. STORCK (2004) e HEINEMANN et al. (2005) relatam maiores concentrações de potássio e fósforo no arroz parboilizado polido comparado ao branco polido, sem efeito na concentração de magnésio. Por outro lado, as concentrações de manganês, zinco e sódio são menores, indicando que os minerais apresentam diferentes padrões de migração durante a parboilização, afetando diferentemente sua concentração nos grãos.

Além do processamento, o genótipo também afeta de forma expressiva o conteúdo de minerais. Estudos têm demonstrado maior concentração de alguns minerais em grãos de arroz com pericarpo vermelho e preto (ITANI et al., 2002; MENG et al., 2005).

Devido à importância do arroz na alimentação, pesquisas vêm sendo desenvolvidas para aumentar a concentração de minerais no grão, principalmente ferro e zinco. Uma das formas utilizadas é o melhoramento convencional, a partir de genótipos com maior concentração destes minerais, visto que existe grande variação na concentração de ferro (2$\left.52 \mu \mathrm{g} \mathrm{g}^{-1}\right)$ e zinco $\left(6-28 \mu \mathrm{g} \mathrm{g}^{-1}\right)$ entre genótipos (JULIANO, 1985). A transgenia também vem sendo utilizada com esse objetivo. VASCONCELOS et al. (2003) avaliaram a introdução no arroz do gene da ferritina da soja, uma proteína armazenadora de ferro. Foram observados aumentos de até quatro vezes na concentração de ferro, tanto no arroz integral $\left(71 \mu \mathrm{g} \mathrm{g}^{-1}\right.$ vs. $\left.15,7 \mu \mathrm{g} \mathrm{g}^{-1}\right)$ quanto no branco polido $\left(37 \mu \mathrm{g} \mathrm{g}^{-1} v \mathrm{~s} .10\right.$ $\left.\mu \mathrm{g} \mathrm{g}^{-1}\right)$. Segundo os autores, o consumo desse arroz pode suprir até 33\% da recomendação diária de ferro com 300 g de grãos. Entretanto, ainda são necessários mais estudos para avaliar a biodisponibilidade deste mineral.

Além do aumento na concentração de ferro, VASCONCELOS et al. (2003) observaram também aumento na concentração de zinco nos grãos com ferritina. O arroz integral apresentou valores máximos de 55,5 $\mu \mathrm{g} \mathrm{g}^{-1}$, comparado ao controle contendo 33,6 $\mu \mathrm{g}$ $\mathrm{g}^{-1}$. Embora não se saiba a razão desse aumento, sabese que a concentração de ferro e zinco no grão está correlacionada, isto é, alterações nos níveis de um afetam os níveis do outro, sugerindo um possível mecanismo regulatório comum.

Vitaminas

O arroz contém principalmente vitaminas do complexo B e $\alpha$-tocoferol (vitamina E), com concentrações insignificantes das vitaminas A, D e C. A concentração é maior nas camadas externas do grão, sendo que, para tiamina, riboflavina, niacina e $\alpha$ tocoferol, aproximadamente 78, 47, 67 e 95\%, respectivamente, estão presentes no farelo (JULIANO, 1993). Dessa forma, o polimento reduz significativamente a concentração de vitaminas (Tabela 3).

Pesquisas vêm sendo desenvolvidas para aumentar a concentração de vitaminas no arroz, 
Tabela 2 - Concentração de minerais em arroz integral e branco polido.

\begin{tabular}{lcc}
\hline Mineral & Arroz integral & Arroz branco polido \\
\hline & Macrominerais $\left(\mathrm{mg} \mathrm{g}^{-1}\right.$, com $14 \%$ de umidade $)$ & \\
Cálcio & $0,1-0,5$ & $0,1-0,3$ \\
Magnésio & $0,2-1,5$ & $0,2-0,5$ \\
Fósforo & $1,7-4,3$ & $0,8-1,5$ \\
Potássio & $0,6-2,8$ & $0,7-1,3$ \\
Silício & $0,6-1,4$ & $0,1-0,4$ \\
Enxofre & $0,3-1,9$ & 0,8 \\
& Microminerais $\left(\mu \mathrm{g} \mathrm{g}^{-1}\right.$, com $14 \%$ de umidade) & \\
Alumínio & $0,3-26,0$ & $0,1-2,2$ \\
Cádmio & $0,02-0,16$ & 0,025 \\
Cloro & $210-560$ & $200-300$ \\
Cobalto & $0,03-0,04$ & 0,017 \\
Cobre & $1-6$ & $2-3$ \\
Iodo & 0,03 & 0,02 \\
Ferro & $2-52$ & $2-28$ \\
Manganês & $2-36$ & $6-17$ \\
Níquel & $0,2-0,5$ & 0,14 \\
Selênio & 0,3 & 0,3 \\
Sódio & $17-340$ & $5-86$ \\
Zinco & $6-28$ & $6-23$ \\
\hline
\end{tabular}

Fonte: Adaptado de JULIANO (1985).

melhorando suas características nutricionais. Entre elas, destacam-se aquelas relacionadas à vitamina A devido à importância de sua deficiência, que atinge milhões de pessoas, e seus efeitos na saúde. As pesquisas levaram à obtenção do Golden rice, um arroz transgênico contendo carotenóides em seu endosperma, precursores da vitamina A. Para obtenção do Golden rice, os pesquisadores avaliaram a expressão no arroz de enzimas importantes na biossíntese da pró-vitamina A, como fitoeno sintase do milho ou de Narcissus pseudonarcissus, caroteno desaturase de Erwinia uredovora e licopeno $\beta$-ciclase de Narcissus pseudonarcissus (BEYER et al., 2002; PAINE et al., 2005). No trabalho desenvolvido por PAINE et al. (2005), foram obtidos grãos contendo $37 \mu \mathrm{g} \mathrm{g}^{-1}$ de carotenóides totais, sendo aproximadamente $84 \%$ de $\beta$-caroteno (principal precursor). Segundo os autores, considerando uma concentração média de $25 \mu \mathrm{g} \mathrm{g}^{-1}$ de $\beta$-caroteno, atinge-se $50 \%$ da recomendação diária de vitamina A para crianças com $72 \mathrm{~g}$ desse arroz. Entretanto, são necessárias mais pesquisas para avaliar outros fatores, como absorção do $\beta$-caroteno e conversão em vitamina A.

Compostos fenólicos

Os compostos fenólicos, ou polifenóis, são metabólitos secundários dos vegetais com diferentes funções nas plantas. Eles podem ser classificados em diferentes grupos, sendo os ácidos fenólicos, os flavonóides e os taninos, os principais na dieta (KING \&YOUNG 1999).

Diversos compostos fenólicos já foram identificados, destacando-se, no arroz, os ácidos fenólicos, principalmente, os ácidos ferúlico e $\rho$ cumárico (TIAN et al., 2004; ZHOU et al., 2004) e, no arroz com pericarpo vermelho e preto, as antocianinas cianidina-3-O- $\beta$-D-glicosídeo e peonidina-3-O- $\beta$-Dglicosídeo (MORIMITSU et al., 2002). Outros compostos identificados no arroz incluem os ácidos vanílico, siríngico, caféico, gálico, protocatéquico, hidroxibenzóico, sinápico e clorogênico, e os ésteres 6'-O-(E)-feruloilsacarose, 6'-O-(E)-sinapoilsacarose e $\gamma$-orizanol (TIAN et al., 2004; ZHOU et al., 2004). No arroz com pericarpo vermelho e preto, também foram identificadas as antocianidinas cianidina e malvidina, procianidinas poliméricas, siringualdeído, vanilina, ácidos $\rho$-cumárico, 4,7-dihidroxivanílico, protocatéquico metil éster, sinápico, ferúlico e caféico, 6'-O-(E)-feruloilsacarose, 6'-O-(E)-sinapoilsacarose e $\gamma$-orizanol (MORIMITSU et al., 2002; HYUN \& CHUNG, 2004). Os polifenóis estão localizados principalmente no pericarpo, sendo a maior parte removida durante o polimento (TIAN et al., 2004), e sua concentração é maior no arroz com pericarpo vermelho e preto (NAM et al., 2005).

Além de suas conhecidas funções nos vegetais, pesquisas têm demonstrado o efeito benéfico de compostos fenólicos de diferentes fontes, inclusive 
Tabela 3 - Conteúdo de vitaminas ( $\mu \mathrm{g} \mathrm{g}^{-1}$ com 14\% de umidade) em arroz integral e branco polido.

\begin{tabular}{lcc}
\hline Vitamina & Arroz integral & Arroz branco polido \\
\hline Retinol $(\mathrm{A})$ & $0-0,11$ & $0-$ tr $^{\text {a }}$ \\
Tiamina $\left(\mathrm{B}_{1}\right)$ & $2,9-6,1$ & $0,2-1,1$ \\
Riboflavina $\left(\mathrm{B}_{2}\right)$ & $0,4-1,4$ & $0,2-0,6$ \\
Niacina $\left(\mathrm{B}_{3}\right)$ & $35-53$ & $13-24$ \\
Ácido pantotênico $\left(\mathrm{B}_{5}\right)$ & $9-15$ & $3-7$ \\
Piridoxina $\left(\mathrm{B}_{6}\right)$ & $5-9$ & $0,4-1,2$ \\
Biotina $\left(\mathrm{B}_{7}\right)$ & $0,04-0,10$ & $0,01-0,06$ \\
Ácido fólico $\left(\mathrm{B}_{9}\right)$ & $0,1-0,5$ & $0,03-0,14$ \\
Cianocobalamina $\left(\mathrm{B}_{12}\right)$ & $0-0,004$ & $0-0,0014$ \\
Ácido $\rho$-aminobenzóico & 0,3 & $0,12-0,14$ \\
$\alpha$-tocoferol $(\mathrm{E})$ & $9-25$ & tr-3 \\
\hline
\end{tabular}

atraços.

Fonte: Adaptado de JULIANO \& BECHTEL (1985).

do arroz, na saúde humana. Este efeito decorre de sua ação antioxidante, auxiliando na prevenção de danos celulares e de doenças crônicas, incluindo doenças cardiovasculares, envelhecimento, diabetes e câncer (KOIDE et al., 1996; XIA et al., 2003; HYUN \& CHUNG, 2004). No arroz, maior atividade antioxidante é observada nos grãos integrais e naqueles com pericarpo vermelho e preto, devido à maior concentração de polifenóis (NAM et al., 2005).

\section{Ácido fítico}

O ácido fítico (mioinositol hexafosfato, IP6) é uma forma de armazenamento de fósforo, constituindo aproximadamente $70 \%$ do conteúdo desse mineral em sementes. Ele pode ser encontrado na forma de fitato, ligado a cátions como potássio, magnésio, cálcio, ferro e zinco (LIU et al., 2005a). O teor é maior nas camadas externas do grão (aproximadamente 88\%), estando associado principalmente à camada de aleurona. Dessa forma, o polimento resulta em redução significativa da sua concentração, como observado por HUNT et al. (2002), que obtiveram 0,065\% de ácido fítico para o arroz branco polido, comparado a $0,78 \%$ para o arroz integral. Também são observadas diferenças genotípicas na sua concentração (LIU et al., 2005a).

Devido a sua capacidade quelante, historicamente o ácido fítico tem sido considerado um composto com ação prejudicial à nutrição, contribuindo para a menor absorção de vários minerais importantes, como cálcio, ferro e zinco, podendo provocar deficiências (HURRELL et al., 2003). Entretanto, pesquisas têm demonstrado que esse composto pode auxiliar na manutenção da saúde. Devido a sua capacidade de quelar ferro, o qual participa de reações oxidantes, ele apresenta efeito antioxidante (GRAF \& EATON, 1990). O ácido fítico também tem sido relacionado à redução nos riscos de desenvolvimento de diferentes tipos de câncer devido a sua ação antioxidante, redução da proliferação celular (GRAF \& EATON, 1990), indução à diferenciação celular (SHAMSUDDIN et al., 1997) e à apoptose (VERGHESE et al., 2006). LEE et al. (2005) e LEE et al. (2006) relatam também a redução de lipídios no soro e no fígado e dos níveis sangüíneos de glicose em ratos diabéticos, podendo assim auxiliar no controle do diabetes.

\section{CONCLUSÕES}

As variações na composição do arroz, tanto devido ao genótipo quanto ao processamento, são interessantes para a alimentação, devido à diferença nas características nutricionais, podendo-se utilizar o arroz com diferentes fins na dieta. Por exemplo, grãos com menor índice glicêmico podem ser indicados para auxiliar na prevenção e/ou no controle do diabetes, grãos com maior teor de minerais podem ser indicados para pessoas em risco nutricional por deficiência da ingestão desses micronutrientes, entre outros. Devese salientar que a principal forma de consumo do grão, o arroz branco polido, apresenta redução na concentração da maioria dos nutrientes, afetando significativamente as características nutricionais. O arroz apresenta efeito positivo na prevenção de diversas doenças crônicas devido a diferentes constituintes, mas é deficiente em alguns nutrientes. Nos últimos anos, pesquisas vêm sendo desenvolvidas visando contornar esses problemas, utilizando tanto o melhoramento convencional como a transgenia, obtendo-se grãos com características nutricionais mais interessantes para o consumo humano. Cada vez mais, o arroz se destaca não somente como um dos principais alimentos para a população, mas também como um alimento de qualidade, que pode auxiliar na manutenção da saúde, devendo ser incentivada a produção desse cereal e a continuidade das pesquisas.

Ciência Rural, v.38, n.4, jul, 2008. 


\section{AGRADECIMENTOS}

Ao Conselho Nacional de Desenvolvimento Científico e Tecnológico (CNPq), pelas bolsas de estudo e produtividade dos autores.

\section{REFERÊNCIAS}

BEHALL, K.M. et al. Whole-grain diets reduce blood pressure in mildly hypercholesterolemic men and women. Journal of the American Dietetic Association, v.106, p.1445-1449, 2006.

BEYER, P. et al. Golden rice: introducing the $\beta$-carotene biosynthesis pathway into rice endosperm by genetic engineering to defeat vitamin A deficiency. Journal of Nutrition, v.132, p.506S-510S, 2002

FAO - Food and Agriculture Organization of the United Nations. Statistical databases. Capturado em 15 abr. 2006. Online. Disponível na Internet: http://www.fao.org.

FREI, M. et al. Studies on in vitro starch digestibility and the glycemic index of six different indigenous rice cultivars from the Philippines. Food Chemistry, v.83, p.395-402, 2003.

GODDARD, M.S. et al. The effect of amylose content on insulin and glucose responses to ingested rice. American Journal of Clinical Nutrition, v.39, p.388-392, 1984

GRAF, E.; EATON, J.W. Antioxidant functions of phytic acid. Free Radical Biology and Medicine, v.8, p.61-69, 1990

HEINEMANN, R.J.B. et al. Comparative study of nutrient composition of commercial brown, parboiled and milled rice from Brazil. Journal of Food Composition and Analysis, v.18, n.4, p.287-296, 2005.

HUNT, J.R. et al. Bioavailability of zinc from cooked Philippine milled, undermilled, and brown rice, as assessed in rats by using growth, bone zinc and zinc-65 retention. Journal of Agricultural and Food Chemistry, v.50, p.5229-5235, 2002 .

HURRELL, R.F. et al. Degradation of phytic acid in cereal porridges improves iron absorption by human subjects. American Journal of Clinical Nutrition, v.77, p.12131219, 2003

HYUN, J.W.; CHUNG, H.S. Cyanidin and malvidin from Oryza sativa cv. Heugjinjubyeo mediate cytotoxicity against human monocytic leukemia cells by arrest of $\mathrm{G}_{2} / \mathrm{M}$ phase and induction of apoptosis. Journal of Agricultural and Food Chemistry, v.52, p.2213-2217, 2004.

ITANI, T. et al. Distribution of amylose, nitrogen, and minerals in rice kernels with various characters. Journal of Agricultural and Food Chemistry, v.50, p.5326-5332, 2002.

JENKINS, D.J.A. et al. Glycemic index: overview of implications in health and disease. American Journal of Clinical Nutrition, v.76, p.266S-273S, 2002.

JULIANO, B.O. Polysaccharides, proteins, and lipids of rice. In: JULIANO, B.O. (Ed.). Rice: chemistry and technology. Minnesota, USA: American Association of Cereal Chemists, 1985. Cap.3, p.17-57
JULIANO, B.O. Rice in human nutrition. Rome: FAO, 1993. Capturado em 01 dez. 2006. Online. Disponível na internet: http://www.fao.org.

JULIANO, B.O.; BECHTEL, D.B. The rice grain and its gross composition. In: JULIANO, B.O. (Ed.). Rice: chemistry and technology. Minnesota, USA: American Association of Cereal Chemists, 1985. Cap.2, p.17-57.

KATSUBE, T. et al. Accumulation of soybean glycinin and its assembly with the glutelins in rice. Plant Physiology, v.120, p.1063-1073, 1999

KENNEDY, G. et al. Nutrient impact assessment of rice in major rice-consuming countries. International Rice Commission Newsletter, v.51, p.33-42, 2002.

KING, A.; YOUNG, G. Characteristics and occurrence of phenolic phytochemical. Journal of the American Dietetic Association, v.99, p.213-218, 1999

KOIDE, T. et al. Antitumor effect of hydrolyzed anthocyanin from grape rinds and red rice. Cancer Biotherapy and Radiopharmacology, v.11, n.4, p.273-277, 1996.

LAI, V.M.F. et al. Non-starch polysaccharide compositions of rice grains with respect to rice variety and degree of milling. Food Chemistry, v.101, p.1205-1210, 2006.

LEE, S.H. et al. Effects of dietary phytic acid on serum and hepatic lipid levels in diabetic KK mice. Nutrition Research, v.25, p.869-876, 2005.

LEE, S.H. et al. Dietary phytic acid lowers the blood glucose level in diabetic KK mice. Nutrition Research, v.26, p.474479, 2006.

LEE, T.T.T. et al. Enhanced methionine and cysteine levels in transgenic rice seeds by the accumulation of sesame $2 \mathrm{~S}$ albumin. Bioscience, Biotechnology, and Biochemistry, v.67, n.8, p.1699-1705, 2003

LI, J. et al. Long-term effects of high dietary fiber intake on glucose tolerance and lipid metabolism in GK rats: comparison among barley, rice, and cornstarch. Metabolism, v.52, n.9, p.1206-1210, 2003.

LIU, Z.H. et al. Grain phytic acid content in japonica rice as affected by cultivar and environment and its relation to protein content. Food Chemistry, v.89, n.1, p.49-52, 2005a.

LIU, Z.H. et al. Positional variations in phytic acid and protein content within a panicle of japonica rice. Journal of Cereal Science, v.41, p.297-303, 2005b.

LUMEN, B.O.; CHOW, H. Nutritional quality of rice endosperm. In: LUH, B. S. (Ed.). Rice utilization. 2.ed. New York: Van Nostrand Reinhold, 1995. V.2, cap.15, p.363-395.

MANO, Y. et al. Comparative composition of brown rice lipids (lipid fractions) of indica and japonica rices. Bioscience, Biotechnology, and Biochemistry, v.63, n.4, p.619-626, 1999.

MATSUO, T. et al. Science of the rice plant. V. II Physiology. Tokyo: Food and Agriculture Policy Research Center, 1995. 1245p.

Ciência Rural, v.38, n.4, jul, 2008. 
MENG, F. et al. Iron content and bioavailability in rice. Journal of Trace Elements in Medicine and Biology, v.18, p.333-338, 2005.

MILLER, J.B. et al. Rice: a high or low glycemic index food? American Journal of Clinical Nutrition, v.56, p.10341036, 1992.

MORIMITSU, Y. et al. Inhibitory effect of anthocyanins and colored rice on diabetic cataract formation in the rat lenses. International Congress Series, v.1245, p.503-508, 2002.

NAM, S.H. et al. Antioxidative, antimutagenic, and anticarcinogenic activities of rice bran extracts in chemical and cell assays. Journal of Agricultural and Food Chemistry, v.53, p.816-822, 2005.

ONG, M.H.; BLANSHARD, J.M.V. Texture determinants in cooked, parboiled rice I: rice starch amylose and the fine structure of amylopectin. Journal of Cereal Science, v.21, p.251260, 1995.

PAINE, J. A. et al. Improving the nutritional value of Golden Rice through increased pro-vitamin A content. Nature Biotechnology, v.23, n.4, p.482-487, 2005.

QURESHI, A.A. et al. Novel tocotrienols of rice bran modulate cardiovascular disease risk parameters of hypercholesterolemic humans. Nutritional Biochemistry, v.8, p.290-298, 1997.

RONG, N. et al. Oryzanol decreases cholesterol absorption and aortic fatty streaks in hamsters. Lipids, v.32, n.3, p.303-309, 1997.

SAIKUSA, T. et al. Distribution of free amino acids in the rice kernel and kernel fractions and the effect of water soaking on the distribution. Journal of Agricultural and Food Chemistry, v.42, p.1122-1125, 1994.

SHAMSUDDIN, A.M. et al. IP6: a novel anti-cancer agent. Life Sciences, v.61, p.343-354, 1997.

SINDHU, A.S. et al. The pea seed storage protein legumin was synthesized, processed, and accumulated stably in transgenic rice endosperm. Plant Science, v.130, n.2, p.189-196, 1997.

STORCK, C.R. Variação na composição química em grãos de arroz submetidos a diferentes beneficiamentos. 2004. 108f. Dissertação (Mestrado em Ciência e Tecnologia de Alimentos) - Curso de Pós-graduação em Ciência e Tecnologia de Alimentos, Universidade Federal de Santa Maria.
TAIRA, H.; ITANI, T. Lipid content and fatty acid composition of brown rice of cultivars of the United States. Journal of Agricultural and Food Chemistry, v.36, p.460-462, 1988.

TIAN, S. et al. Analysis of phenolic compounds in white rice, brown rice, and germinated brown rice. Journal of Agricultural and Food Chemistry, v.52, p.4808-4813, 2004.

TRAN, T.U. et al. Analysis of the tastes of brown rice and milled rice with different milling yields using a taste sensing system. Food Chemistry, v.88, p.557-566, 2004.

VASCONCELOS, M. et al. Enhanced iron and zinc accumulation in transgenic rice with the ferritin gene. Plant Science, v.164, p.371-378, 2003.

VELANGI, A. et al. Evaluation of a glucose meter for determining the glycemic responses of foods. Clinical Chimica Acta, v.356, p.191-198, 2005.

VERGHESE, M. et al. Anticarcinogenic effect of phytic acid (IP6): apoptosis as a possible mechanism of action. LWT Food Science and Technology, v.39, p.1093-1098, 2006.

VISSERS, M.N. et al. Effect of plant sterols from rice bran oil and triterpene alcohols from sheanut oil on serum lipoprotein concentrations in humans. American Journal of Clinical Nutrition, v.72, p.1510-1515, 2000.

WARNER, A.C.I. Rate of passage of digesta through the gut of mammals and birds. Nutrition Abstracts Reb, v.51, p.789975, 1981.

XIA, M. et al. Supplementation of diets with the black rice pigment fraction attenuates atherosclerotic plaque formation in apolipoprotein E deficient mice. Journal of Nutrition, v.133, n.3, p.744-751, 2003.

ZHENG, Z. et al. The bean seed storage protein $\beta$-phaseolin is synthesized, processed, and accumulated in the vacuolar typeII protein bodies of transgenic rice endosperm. Plant Physiology, v.109, p.777-786, 1995.

ZHOU, Z. et al. Composition and functional properties of rice. International Journal of Food Science and Technology, v.37, p.849-868, 2002.

ZHOU, Z. et al. The distribution of phenolic acids in rice. Food Chemistry, v.87, p.401-406, 2004. 